\title{
Spectroscopic Identification of Hydrogen Bond Vibrations and Quasi-Isostructural Polymorphism in N-Salicylideneaniline
}

\author{
Łukasz Hetmańczyk ${ }^{1}$, Eugene A. Goremychkin ${ }^{2}$, Janusz Waliszewski ${ }^{3}$, Mikhail V. Vener ${ }^{4,5}\left({ }^{\circledR}\right.$, \\ Paweł Lipkowski ${ }^{6}\left(\mathbb{D}\right.$, Peter M. Tolstoy ${ }^{7, *}$ and Aleksander Filarowski ${ }^{2,8, * \mathbb{D}}$ \\ 1 Faculty of Chemistry, Jagiellonian University, 2 Gronostajowa Str., 30-387 Cracow, Poland; \\ lukasz.hetmanczyk@uj.edu.pl \\ 2 Frank Laboratory of Neutron Physics, Joint Institute for Nuclear Research 6 F. Joliot-Curie str., \\ 141980 Dubna, Russia; goremychkin@jinr.ru \\ 3 Faculty of Physics, University of Bialystok, 1L Ciolkowskiego str., 15-245 Bialystok, Poland; \\ j.waliszewski@uwb.edu.pl \\ 4 Quantum Chemistry Department, Mendeleev University of Chemical Technology, Miusskaya Square 9, \\ 125047 Moscow, Russia; venermv@muctr.ru \\ 5 Kurnakov Institute of General and Inorganic Chemistry, Russian Academy of Sciences, Leninskii Prosp. 31, \\ 119991 Moscow, Russia \\ 6 Department of Physical and Quantum Chemistry, Wrocław University of Science and Technology, Wybrzeże \\ Wyspiańnskiego 27, 50-370 Wrocław, Poland; pawel.lipkowski@pwr.edu.pl \\ 7 Institute of Chemistry, St. Petersburg State University, Universitetskij pr. 26, 198504 Saint Petersburg, Russia \\ 8 Faculty of Chemistry, University of Wrocław 14 F. Joliot-Curie str., 50-383 Wrocław, Poland \\ check for \\ updates \\ * Correspondence: peter.tolstoy@spbu.ru (P.M.T.); aleksander.filarowski@chem.uni.wroc.pl (A.F.); \\ Tel.: +48-71-375-7229 (A.F.)
}

Citation: Hetmańczyk, Ł.;

Goremychkin, E.A.; Waliszewski, J.;

Vener, M.V.; Lipkowski, P.; Tolstoy,

P.M.; Filarowski, A. Spectroscopic

Identification of Hydrogen Bond

Vibrations and Quasi-Isostructural

Polymorphism in

N-Salicylideneaniline. Molecules 2021

26, 5043. https://doi.org/10.3390/

molecules26165043

Academic Editor: Mirosław Jabłoński

Received: 31 July 2021

Accepted: 16 August 2021

Published: 20 August 2021

Publisher's Note: MDPI stays neutral with regard to jurisdictional claims in published maps and institutional affiliations.

Copyright: (c) 2021 by the authors. Licensee MDPI, Basel, Switzerland. This article is an open access article distributed under the terms and conditions of the Creative Commons Attribution (CC BY) license (https:/ / creativecommons.org/licenses/by/ $4.0 /)$.

\begin{abstract}
The ortho-hydroxy aryl Schiff base 2-[(E)-(phenylimino)methyl]phenol and its deuteroderivative have been studied by the inelastic incoherent neutron scattering (IINS), infrared (IR) and Raman experimental methods, as well as by Density Functional Theory (DFT) and DensityFunctional Perturbation Theory (DFPT) simulations. The assignments of vibrational modes within the $3500-50 \mathrm{~cm}^{-1}$ spectral region made it possible to state that the strong hydrogen bond in the studied compound can be classified as the so-called quasi-aromatic bond. The isotopic substitution supplemented by the results of DFT calculations allowed us to identify vibrational bands associated with all five major hydrogen bond vibrations. Quasi-isostructural polymorphism of 2-[(E)-(phenylimino)methyl]phenol (SA) and 2-[(E)-(phenyl-D5-imino)methyl]phenol $\left(\mathbf{S A}-\mathbf{C}_{6} \mathbf{D}_{5}\right)$ has been studied by powder X-ray diffraction in the $20-320 \mathrm{~K}$ temperature range.
\end{abstract}

Keywords: Schiff bases; inelastic incoherent neutron scattering; hydrogen bond; isotopic effect

\section{Introduction}

This paper dwells on the studies of one of the most popular photo-thermochromic compounds, 2-[(E)-(phenylimino)methyl]phenol (N-salicylideneaniline), from the group of the ortho-hydroxy aryl Schiff bases. The first compounds of this type were synthesized in 1864 by Hugo Schiff [1] and have attracted attention ever since [2,3]. The ortho-hydroxy aryl Schiff bases, and materials based on them, demonstrate a number of interesting and useful characteristics. For example, they manifest polymorphic properties [4], ionic liquids' properties [5], elastic bending capability [6] and recognised anti-cancer properties [7]. The chiral aldimines possess the photochromic feature in the crystalline state, caused by photoinduced proton transfer in the intramolecular OHN hydrogen bond [8,9]. The chiroptical and optical anisotropic properties of photomechanical Schiff bases were previously studied under UV irradiation [10]. Such properties as ferroelectricity, piezoelectricity and second-order optical non-linearity were reported [11,12].

Many of the abovementioned features are linked to the existence of an intramolecular OHN hydrogen bond and to various conformational changes that ortho-hydroxy aryl Schiff 
bases could undergo. The conformational changes in the excited state were first studied in the year 1962 [13] and continue to attract attention to date. The development of new synthetic routes led to a significant increase in the number of available compounds and allowed novel types of liquid crystals and photo-optical switches to be obtained [14]. Such characteristics are usually conditioned by the isomerization of the imine fragment [15-18]. Besides, isomerization of an ortho-hydroxy aryl Schiff base attached to a BODIPY chromophore was used to tune its UV absorption spectra [19].

A long discussion takes place in the literature [20-30] on what intramolecular changes are responsible for the emergence and fine tuning of photo-thermochromic properties of ortho-hydroxy aryl Schiff bases: isomerization of the hydroxyl- and imine- groups (Chart a, Figure 1) or intramolecular proton transfer with the consequent isomerization of the amino group (Chart b, Figure 1) or aniline ring rotation (Chart c, Figure 1).<smiles>Oc1ccccc1/C=N/c1ccccc1</smiles>

(a)

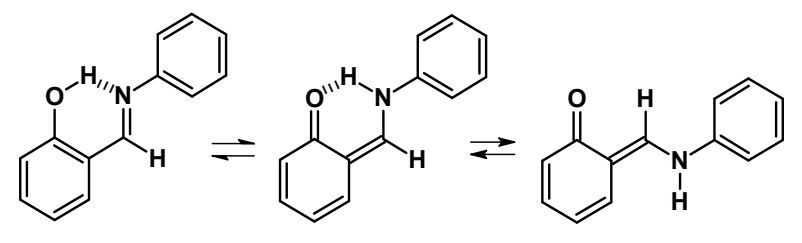

(b)

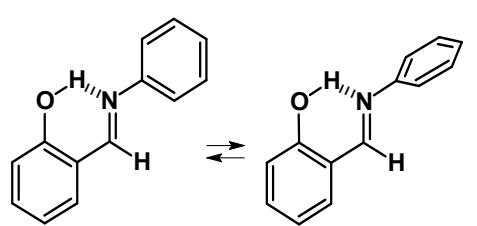

(c)

Figure 1. Conformational equilibria of 2-[(E)-(phenylimino)methyl]phenol.

The recent comprehensive studies seem to indicate that the proton transfer in the intramolecular OHN hydrogen bond and the isomerization of the aldimine fragment (Chart b, Figure 1) is in charge of the appearance of photo-thermochromic properties in ortho-hydroxy aryl Schiff bases [28]. Notably, the strength of the hydrogen bond and tautomeric equilibrium in it are linked to the observation of certain physical-chemical properties. In cases where the $\mathrm{OH}$ tautomeric form is prevailing, it is possible to observe $\mathrm{OH}$ isomerization, leading to the absence of photo-thermochromic properties, Chart a. Recently, Mielke et al. [29,30] have discovered the existence of the trans-OH form in the specific condition of matrix isolation. However, the prevailing of the $\mathrm{NH}$ tautomeric form makes it possible to observe the isomerization of the amino group (Chart b) and, therefore, the emergence of photo-thermochromic properties. It is important to underline the contribution by Ogawa et al. [24] who were the first to show the existence of trans$\mathrm{NH}$ form in the solid state by X-ray method. The possibility of rotation of aldimine ring (Chart c) was first demonstrated by Cohen et al. $[13,20]$, and later it was associated with the appearance of polymorphism of the studied compound.

The conformational changes, occurring in ortho-hydroxy aryl Schiff bases in different conditions and states, were investigated mostly by the methods of vibrational spectroscopy in the middle spectral range [29-36], while the low- and high-frequency hydrogen bridge vibrations have never been in the focus of the spectroscopic studies before. Therefore, in order to fill in the gap, we have synthesized 2-[(E)-(phenylimino)methyl]phenol (Nsalicylideneaniline, $\mathbf{S A}$ ) and its deutero-derivatives (SA-OD and $\mathbf{S A}-\mathbf{C}_{6} \mathbf{D}_{5}$, see Figure 2) to analyse the vibrational spectra measured by IINS, Raman and IR methods. The quantummechanical DFT and DFPT calculations, as well as Potential Energy Distribution (PED) analysis, have been conducted to assign the spectral bands. The isotopic replacements of the bridged hydrogen for deuterium $(\mathrm{O}-\mathrm{H} \cdots \mathrm{N} \rightarrow \mathrm{O}-\mathrm{D} \cdots \mathrm{N})$ and the hydrogen atoms for the deuterium atoms in aldimine ring $\left(\mathrm{NC}_{6} \mathrm{H}_{5} \rightarrow \mathrm{NC}_{6} \mathrm{D}_{5}\right)$ were performed to additionally confirm the assignment. To that end, the Isotopic Spectral Ratios (ISRs) were used, which are defined for a given vibrational mode as the ratio of frequencies for non-deuterated and deuterated species. The ISR values are well studied for high-frequency stretching and bending proton vibrations [37], but poorly studied for the low-frequency hydrogen bridge vibrations. 
<smiles>[CH]1Oc2ccccc2C1=Nc1ccccc1</smiles>

SA<smiles>c1ccc(N2[P]Oc3ccccc32)cc1</smiles>

SA-OD<smiles>[2H]c1c([2H])c([2H])c(N2[CH]Oc3ccccc3C2=N)c([2H])c1[2H]</smiles>

SA-C ${ }_{6} \mathrm{D}_{5}$

Figure 2. Structures of studied 2-[(E)-(phenylimino)methyl]phenol and its isotopologues.

Moreover, this paper delves into the spectroscopic manifestations of polymorphism of N-salicylideneaniline and its isotopologues in a wider temperature range in 20-320 K. $\mathrm{N}$-salicylideneaniline was studied earlier in papers $[27,28]$ in the $100-320 \mathrm{~K}$ temperature range.

\section{Results and Discussion}

\subsection{Assignment of Hydrogen Bonding Vibrations}

This part of the paper focuses on the assignments of the spectral bands to the vibrations involving the hydroxyl group $(\gamma(\mathrm{OH}), \delta(\mathrm{OH})$ and $\gamma(\mathrm{OH})))$ and the hydrogen bridge $\left(v_{\sigma}(\mathrm{ON})\right.$ and $\left.v_{\beta}(\mathrm{ON})\right)$, Scheme 1 , continuing and expanding our studies started in Ref. [38].

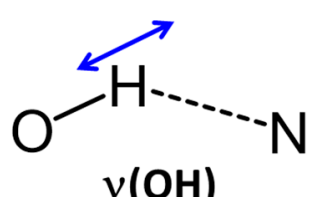

$v(\mathrm{OH})$<smiles></smiles><smiles></smiles>

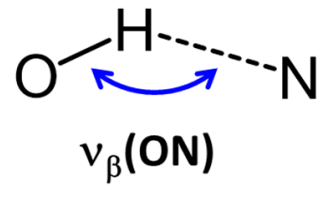

Scheme 1. The OHN hydrogen bond vibrations of the studied 2-[(E)-(phenylimino)methyl]phenols.

We start the discussion with the high-frequency region of vibrational spectra, which are presented in Figure S1 in the supporting information for brevity. The broad band located within the range of $2900-1500 \mathrm{~cm}^{-1}$ in the measured infrared spectrum is assigned to the stretching vibrations $v(\mathrm{OH})$ as a result of the comparison of the spectra of the nondeuterated and deuterated isopologues (ISR =1.320). This band is characteristic for $\mathrm{OH}$ form of Schiff bases (enol-imine) and not to $\mathrm{NH}$ form (keto-amine). The $v(\mathrm{OH})$ band is rather wide and can be assigned to the so-called Zundel's continuum absorption [39]. This fact proves that the hydrogen bond in these compounds is strong. Moreover, the intensity of the $v(\mathrm{OH})$ band is rather weak despite its noticeable shift towards lower frequencies, which indicates that the hydrogen bond in SA is a quasi-aromatic one, which is also referred to as resonance-assisted hydrogen bond (RAHB) [40-48].

The low-frequency region of the IR, Raman and IINS spectra of non-deuterated (SA) and deuterated (SA-OD) compounds are shown in Figure 3. The experimental spectra were interpreted using the calculated vibrational spectra (DFT) and the results of the PED analysis (Tables S2-S4). 


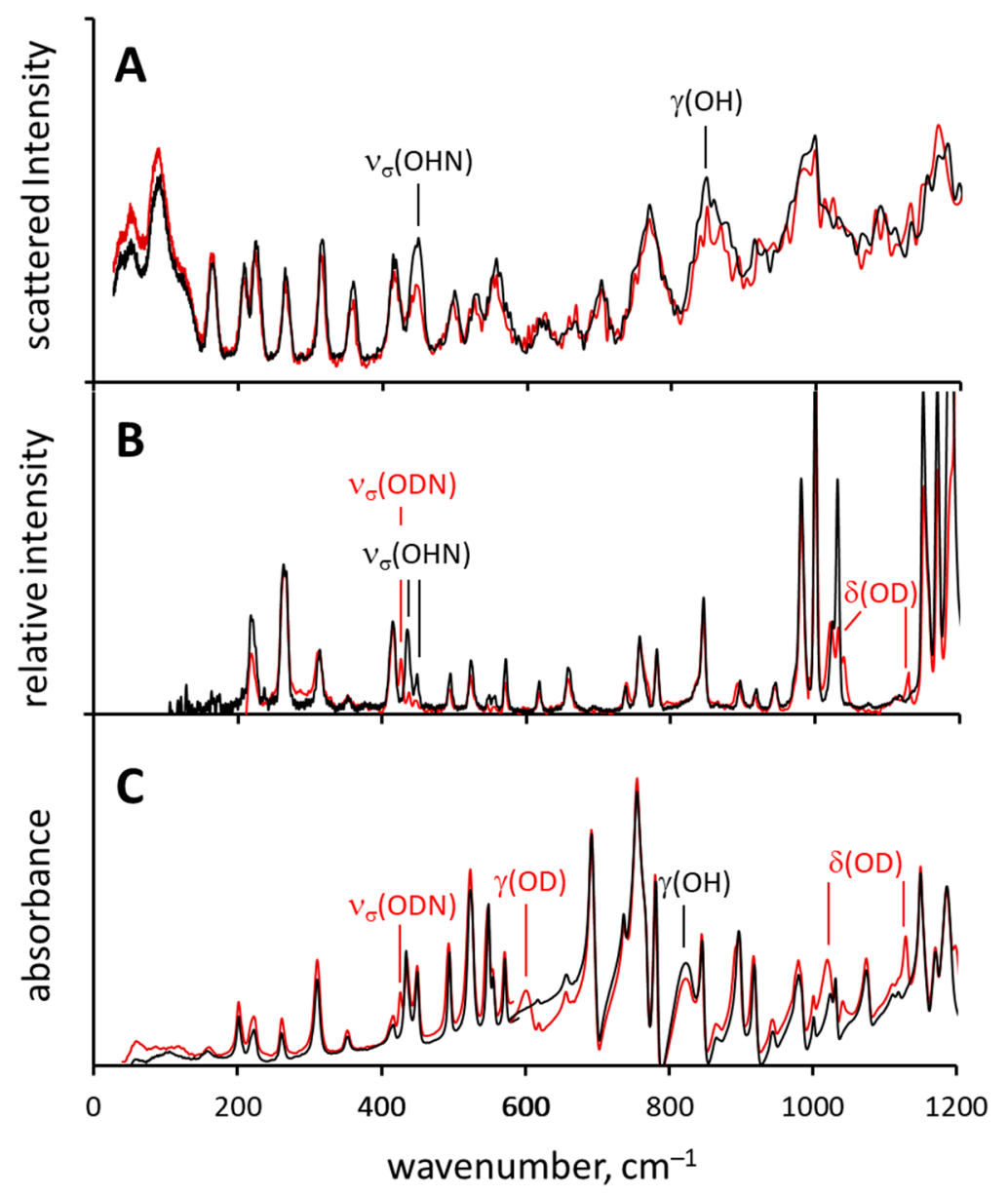

Figure 3. Normalized experimental IINS (A), Raman (B) and IR (C) spectra of SA (black line) and its deuterated derivative SA-OD (red lines).

When it comes to the in-plane deformational vibrations $\delta(\mathrm{OH})$, they are not characteristic for ortho-hydroxy Schiff bases [33,35,38]. According to PED analysis, $\delta(\mathrm{OH})$ vibration is mixed with the $v\left(\mathrm{C}_{\mathrm{alk}} \mathrm{C}_{\text {alk }}\right)$ and $\gamma(\mathrm{CH})$ vibrations. After the $\mathrm{OH} \rightarrow \mathrm{OD}$ substitution the bands located at 1571 and $1484 \mathrm{~cm}^{-1}$ (both IR and Raman active) decrease in intensity and shift slightly, while the more characteristic $\delta(\mathrm{OD})$ bands appear at ca. $1130 \mathrm{~cm}^{-1}$ and ca. $1020 \mathrm{~cm}^{-1}$ both in IR and Raman spectra of SA-OD (Figure 3).

As for the out-of-plane deformational vibration $\gamma(\mathrm{OH})$, in the IR spectrum of SA the corresponding band is found in the range of $860-820 \mathrm{~cm}^{-1}$, but it strongly overlaps with the bands of other vibrations and was identified with the help of DFT calculations. However, in the IR spectra of SA-OD this band is clearly visible at $601 \mathrm{~cm}^{-1}$. The $\gamma(\mathrm{OH})$ vibration of SA is practically Raman-inactive, as in the $860-820 \mathrm{~cm}^{-1}$ region of the Raman spectrum there are no clearly identifiable bands which would be sensitive to the $\mathrm{OH} \rightarrow \mathrm{OD}$ replacement. The band at $848 \mathrm{~cm}^{-1}$ in the IINS spectrum drops in intensity after the deuteration and thus it was assigned to the $\gamma(\mathrm{OH})$ vibration. Note, that for IINS method the scattering cross-section for the deutron is much smaller than that of the proton and thus the contribution of the vibrations involving deutrons in IINS spectra is weak. The experimentally observed positions of $\gamma(\mathrm{OH})$ bands and the $\mathrm{H} / \mathrm{D}$ isotope effects on them are consistent with the literature data [49-51].

The stretching vibration of the hydrogen bridge $\left(v_{\sigma}(\mathrm{OHN})\right)$ gives rise to the isotopesensitive bands at $449 \mathrm{~cm}^{-1}$ in the IINS spectrum and two bands at 448 and $434 \mathrm{~cm}^{-1}$ in the Raman spectrum of SA (Figure 3). The intensity of these bands is greatly decreased in the IINS and the Raman spectra of SA-OD, while a new band appears at $425 \mathrm{~cm}^{-1}$ in the Raman spectrum, assigned to the vibration of the ODN bridge, $v_{\sigma}(\mathrm{ODN})$. The 
IINS spectrum does not show the band of the deformational vibration $v_{\beta}(\mathrm{OHN})$ due to insignificant deformational motion of the bridged proton. This phenomenon was described earlier in Ref. [38]. To make the interpretation of the hydrogen bridge vibrations more accurate and reliable, the synthesis of $\mathbf{S A}-\mathbf{C}_{6} \mathbf{D}_{5}$ isotopologue was performed (deuteration in the aldimine ring, $\mathrm{NC}_{6} \mathrm{H}_{5} \rightarrow \mathrm{NC}_{6} \mathrm{D}_{5}$ ). In Figure 4 the IINS spectra of SA, SA-OD and $\mathbf{S A}-\mathbf{C}_{6} \mathbf{D}_{5}$ are compared. Upon deuteration in the hydrogen bridge site (SA-OD), the intensity of the bands assigned to the $\gamma(\mathrm{OH})$ and $v_{\sigma}(\mathrm{OHN})$ vibrations $\left(848 \mathrm{~cm}^{-1}\right.$ and $449 \mathrm{~cm}^{-1}$, respectively) is decreasing (Figure $4 \mathrm{~A}$ ), while the IINS spectrum of the SA- $\mathbf{C}_{6} \mathbf{D}_{5}$ derivative features a more complicated picture (Figure 4B). Firstly, the IINS spectrum of SA- $\mathbf{C}_{6} \mathrm{D}_{5}$ is characterized by the disappearance of a number of bands assigned to $\gamma(\mathrm{CH})$ and $\tau(\mathrm{CH})$ vibrations, which were located at 1183, 1175, 1153, 1089, 703 and $521 \mathrm{~cm}^{-1}$ in the spectrum of SA (see blue arrows in Figure 4). Secondly, the bands visible at 208, 264,359 and $495 \mathrm{~cm}^{-1}$ in the spectrum of SA (see red arrows in Figure 4B) shift to lower frequencies, namely, to 202, 255, 345 and $491 \mathrm{~cm}^{-1}$, respectively. The intensity of the first three bands is decreasing, while that of the fourth one is increasing slightly. Judging from Tables S2 and S4, these bands stem from the skeleton vibrations of the aldimine ring, where the deuteration occurs.

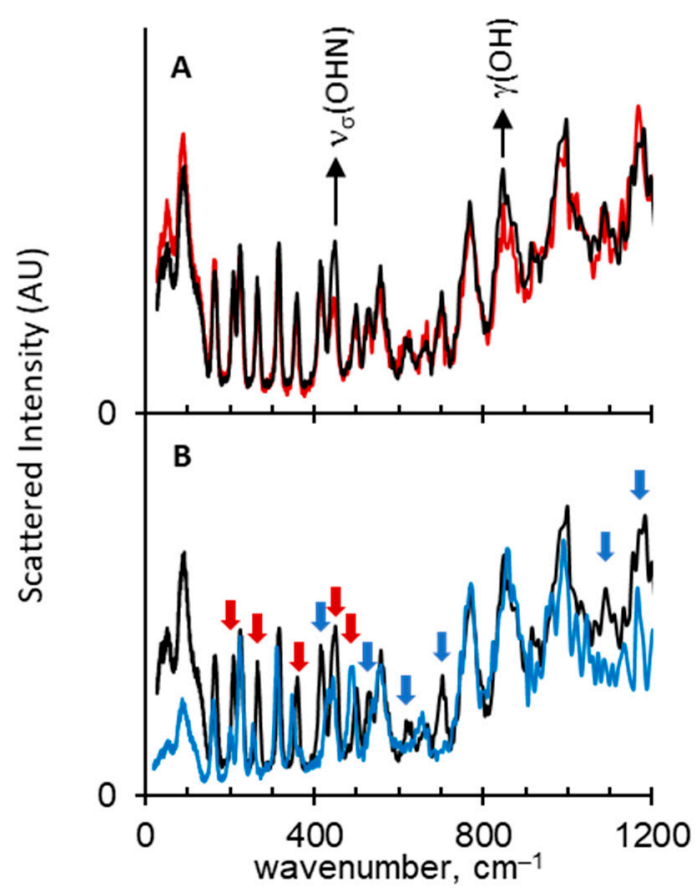

Figure 4. Normalized IINS spectra of SA (black traces), SA-OD (panel (A), red trace) and SA- $\mathbf{C}_{6} \mathbf{D}_{5}$ (panel (B), blue trace). Blue arrows: bands of $\gamma(\mathrm{CH})$ and $\tau(\mathrm{CH})$ vibrations, which disappear after deuteration. Red arrows: bands of various vibrations, which shift after the deuteration. See text for more details.

The band at $449 \mathrm{~cm}^{-1}$, which is assigned to $v_{\sigma}(\mathrm{OHN})$ vibration (also marked by the red arrow in Figure 4B), is also sensitive to deuteration in the aldimine ring: the band broadens and its peak intensity decreases. Such a long-range H/D isotope effect on hydrogen bond vibrations is reported here for the first time. Below in Section 2.3 it is shown that $\mathbf{S A}$ exists as a mixture of two quasi-isostructural polymorphs and the shift of the $v_{\sigma}(\mathrm{OHN})$ band might be associated with the change of the mole fractions of these polymorphs upon $\mathbf{S A} \rightarrow \mathbf{S A}-\mathbf{C}_{6} \mathbf{D}_{5}$ deuteration, though this question requires additional consideration which is beyond the scope of this work. 


\subsection{Spectral Manifestations of Polymorphism}

The SA could crystallize in three polymorphic states-called $\alpha_{1}, \alpha_{2}$ and $\beta$-the crystal structures and cell packing of which were earlier published by F. Arod in papers [27,28]; for a visual representation of the cell packing see Figure 2 (polymorph $\beta$ ) and Figure 8 (polymorphs $\alpha_{1}$ and $\alpha_{2}$ ) in [27]. All three polymorphs exhibit enol-imine form with intramolecular $\mathrm{OH} \cdots \mathrm{N}$ hydrogen bond. These polymorphs differ only slightly in molecular positions and conformations, representing "very close points in the crystal structure landscape" [52-54]; one of the larger differences between $\alpha$ and $\beta$ states is the rotational conformation of the aldimine ring (Chart c, Figure 1). The polymorphs $\alpha_{1}$ and $\alpha_{2}$ are called quasi-isostructural. The structural mobility and polymorphism of different compounds [55-59], and Schiff bases in that number [60,61], was investigated by various methods. In this part of the paper our goal was to determine if vibrational spectra could be used to unambiguously identify the particular polymorphic state and which vibrational marker modes would be most informative. For that purpose, the crystallographic structures of polymorphs $\alpha_{2}$ and $\beta$ were optimized with CRYSTAL software, the IR spectra were calculated by DFPT method and compared with the experimental one. The result of the comparison is shown in Figure 5. There is a reasonably good agreement-both in bands positions and their relative intensities-between the experimental spectrum (Figure 5A) obtained at $295 \mathrm{~K}$ in which polymorph $\alpha_{2}$ prevails and the calculated spectrum of polymorph $\alpha_{2}$ (Figure $5 \mathrm{~B}$ ), while the agreement with that of polymorph $\beta$ is significantly worse (Figure 5C). The most informative bands are marked by asterisks in Figure 5A,B. These bands are assigned to the following vibrations: $v(\mathrm{C}=\mathrm{N}), v\left(\mathrm{C}_{\mathrm{ar}} \mathrm{C}_{\mathrm{ar}}\right), \gamma(\mathrm{CH}), \tau(\mathrm{CH})$ and $\tau(C C)$.

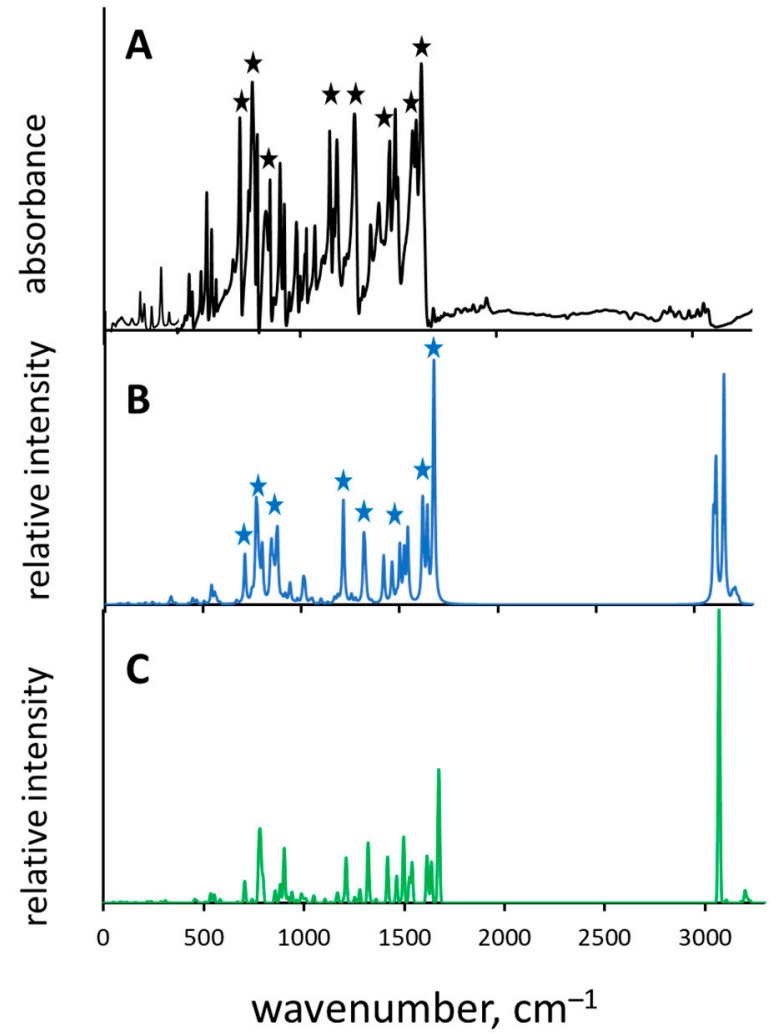

Figure 5. Normalized IR experimental ((A), black trace; measured at $295 \mathrm{~K})$ and calculated by DFPT method spectra of polymorphs $\alpha_{2}((\mathbf{B})$, blue trace) and $\beta((\mathbf{C})$, green trace) of SA. Black and blue asterisks: the most informative bands, allowing one to identify polymorph $\alpha_{2}$. See text for more details. 
The abovementioned observations support the applicability of DFPT computational method for the research of polymorphic states.

\subsection{X-ray Powder Diffraction (XPD) Study of Polymorphism in $S A$}

$X$-ray Powder Diffraction measurements of $\mathbf{S A}$ and $\mathbf{S A}-\mathbf{C}_{6} \mathbf{D}_{5}$ were carried out in the 20-320 K temperature range. The X-ray diffraction pattern for SA-OD is not discussed here, because the results closely match those for $\mathbf{S A}$. The experiments revealed that both SA and $\mathbf{S A}-\mathrm{C}_{6} \mathrm{D}_{5}$ crystallize in a triclinic form, which is in agreement with the single crystal $\mathrm{X}$-ray data for polymorph $\alpha_{1}$ obtained earlier [27]. For SA, several reflexes are observed as dual signals in the 20-295 K temperature range. As an example, in Figure 6 the reflexes, 002 and $0-11$, for $\mathbf{S A}$ and $\mathbf{S A}-\mathbf{C}_{6} \mathbf{D}_{5}$ are shown. The positions and relative intensities of components of the dual signals are temperature dependent. Similar observations are valid for the deuterated derivative $\mathbf{S A}-\mathbf{C}_{6} \mathbf{D}_{5}$ (Figure $6 \mathrm{C}, \mathrm{D}$ ). Such behaviour is often attributed to the co-existence of two quasi-isostructural polymorphs, preserving the same crystal symmetry [52-56]. In case of SA, following the results of Refs. $[27,28]$ we assign these polymorphs to $\alpha_{1}$ and $\alpha_{2}$ forms.
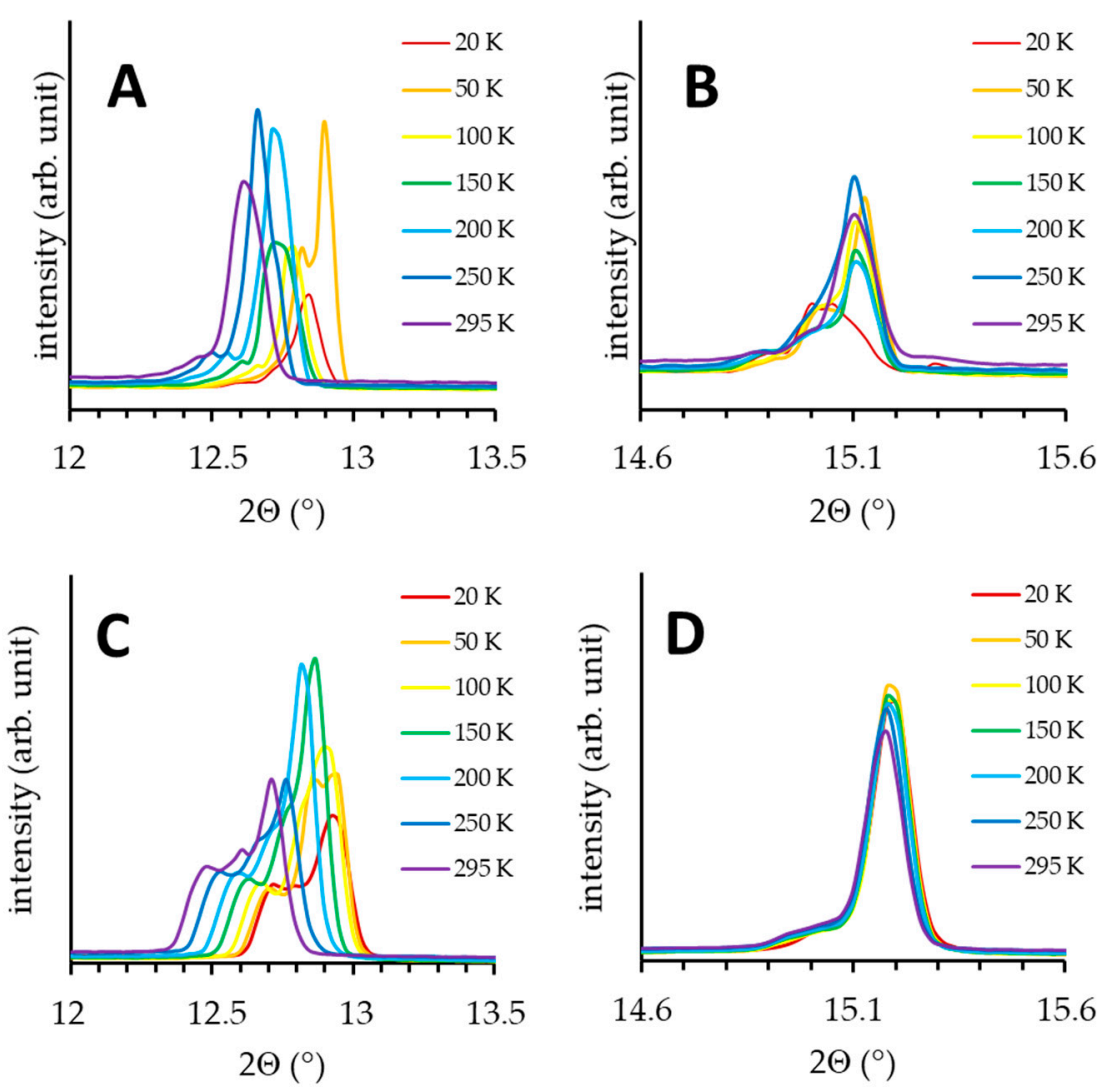

Figure 6. Temperature behaviour of (002) (A,C) and (0-11) (B,D) reflections of SA top (A,B) and SA- $\mathbf{C}_{6} \mathbf{D}_{5}$ bottom $(\mathrm{C}, \mathrm{D})$ panels.

For a better understanding of this phenomenon we performed DFT calculations (in the gas phase) of the potential curves for the rotation of the aldimine fragment of SA in the enol-imine and keto-amine forms. The calculation confirmed that the structure of the keto-amine form is evidently flat and the twist of the aldimine fragment by up to $20^{\circ}$ virtually does not change the potential energy (Figure 7, top). In contrast, the optimized geometry of the enol-imine form is not flat: torsional angle $\Theta(C=N-C=C)=40^{\circ}$ (Figure 7, bottom) and crossing of the phenol ring plane requires to overcome a $1 \mathrm{kcal} / \mathrm{mol}$ barrier. According to the postulate of Benstein et al. [62], such a barrier in a non-homogeneous environment of a crystal lattice could make it possible to obtain two polymorphic forms. 
Though the keto-amine form is less stable than the enol-imine form by ca. $4.6 \mathrm{kcal} / \mathrm{mol}$ and unlikely to be present at room temperature, one could speculate see that the flat structure of the keto-amine form would not be prone to polymorphism.

The keto-amine if the keto-amine form would be,

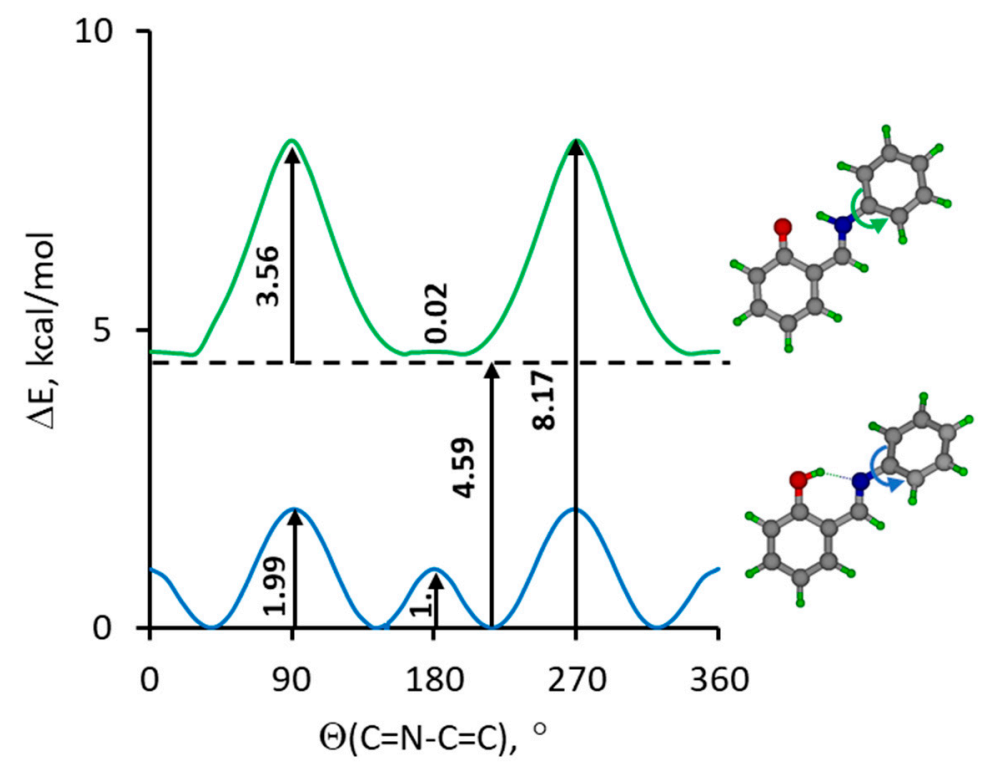

Figure 7. The calculated potential energy profile (B3LYP/6-311++G(d,p)) for a gradual rotation around the $\mathrm{N}-\mathrm{C}$ bond for enol-imine (blue line) and keto-amine (green line) forms of studied Schiff base.

Upon further heating, a significant change of diffractograms of $\mathbf{S A}$ and $\mathbf{S A}-\mathbf{C}_{6} \mathbf{D}_{5}$ is observed at ca. $310 \mathrm{~K}$ (see the set of diffractograms in Figures S2 and S3). Based on the available XPD data, it is difficult to speculate which structural changes are responsible for this, but it is unlikely to be the $\alpha \leftrightarrow \beta$ transition, because the melting temperature of studied crystal was $325 \mathrm{~K}$, coinciding with that previously reported for $\alpha_{1}$ in Ref. [27].

\section{Materials and Methods}

\subsection{Compounds and Deuteration}

2-[(E)-(phenylimino)methyl]phenol (SA) and 2-[(E)-(phenyl-D 5 -imino)methyl]phenol $\left(\mathrm{SA}-\mathrm{C}_{6} \mathrm{D}_{5}\right)$ were synthesized from stoichiometric mixtures of the salicylaldehyde with aniline or aniline- $\mathrm{D}_{5}$ in refluxing methanol, respectively. The solvents were purchased from Sigma-Aldrich and used without further purification. For the deuteration in the mobile proton site, the solution of 2-[(E)-(phenylimino)methyl]phenol in methanol-OD was heated to $60{ }^{\circ} \mathrm{C}$ and refluxed during $30 \mathrm{~min}$, then the methanol was removed by evaporation, leaving SA-OD. The deuteration degree was estimated to be ca. $90 \%$.

\subsection{Infrared, Raman and IINS Measurements}

The infrared measurements were performed using a Bruker Vertex $70 v$ spectrometer. The spectra were collected with a resolution of $2 \mathrm{~cm}^{-1}$. The FT-FIR spectra $\left(500-50 \mathrm{~cm}^{-1}\right)$ were collected for sample suspended in Apiezon $\mathrm{N}$ grease and placed on a polyethylene (PE) disc. The FT-MIR spectra were collected for sample in a KBr pellet. The Raman spectra of the analysed samples were obtained using an FT-Nicolet Magma 860 spectrophotometer. The In:Ga:Ar laser excitation at $1064 \mathrm{~nm}$ was employed for the Raman measurements. The spectra were recorded at the room temperature with the spectral resolution $4 \mathrm{~cm}^{-1}$ and with 512 scans. Neutron scattering data were collected at the pulsed IBR-2 reactor in the Joint Institute of Nuclear Research (Dubna, Russia) using the time-of-flight inverted geometry spectrometer NERA at $10 \mathrm{~K}$ temperature. The experimental features are described in Ref. [50]. 


\subsection{X-ray Powder Diffraction}

The powder X-ray measurements were performed using EMPYREAN equipped with the water-cooled $\mathrm{X}$-ray tube with $\mathrm{Cu}$ anode with the wavelengths of characteristic radiation $\lambda_{\mathrm{CuK} \alpha 1}=1.54056 \AA$ and $\lambda_{\mathrm{CuK} \alpha 2}=1.54443 \AA$. In order to suppress the $\mathrm{K}_{\beta}$ radiation the $\mathrm{Ni}$ filter was used. The central part of the data acquisition system was the silicon strip detector PIXcel. The low temperature measurements were made using the closed cycle helium cryostat Phenix-Oxford Cryosystems.

\subsection{Calculations}

Quantum-mechanical calculations using the B3LYP functional (DFT, the three-parameter exchange hybrid functional of Becke [63], and gradient-corrected correlation functional of Lee, Yang and Parr) [64] with the 6-311++G(d,p) basis set [65-67] were performed for full geometry optimizations with the Gaussian 16 Rev. C01 suite of program [68]. The structures were visualized by the MOLDEN program [69]. The potential energy distribution (PED) of the normal modes was calculated in terms of natural internal coordinates using the Gar2ped program [70]. Static periodic (solid-state) DFT calculations (DFPT Density-Functional Perturbation Theory) were performed in the CRYSTAL09 [71,72] software package using the B3LYP functional with the Grimme D2 dispersion correction [73] and 6-31G $\mathrm{G}^{* *}$ basis set [67]. The space groups and unit cell parameters of the considered crystals obtained in the experimental studies $[27,28]$ were fixed and structural relaxations were limited to the position of atoms. Such approximation gives a reasonable description of the structure and spectroscopic features of intra- and intermolecular H-bonds of different types and strengths in molecular crystals [74-76]. The experimental atomic positions were used as the starting point in the periodic DFT computations. Periodic DFT computations were conducted for polymorphs $\alpha_{2}$ and $\beta$. The disordered $\alpha_{1}$-polymorph [27] is not suitable for periodic calculations. Since $\alpha_{1}$ and $\alpha_{2}$ polymorphs are quasi-isostructural, we assumed that their IR spectra are very close to each other. Therefore, only the IR spectrum of the second polymorph was considered in the present study. Periodic DFT computations of $\alpha_{2}$-polymorph led to the appearance of imaginary frequencies. This problem is usually solved by reducing the space symmetry of a crystal $[77,78]$. Reducing the space symmetry group to P1 allowed us to get rid of imaginary frequencies of $\alpha_{2}$-polymorph. An accurate interpretation of the experimental spectrum assumes knowledge of the relative stability of polymorphs $\alpha_{2}$ and $\beta$. This requires the calculation of the sublimation enthalpy, which is very cumbersome in the case of conformationally mobile molecules [79]. In addition, the error in the calculated values can reach $15 \mathrm{~kJ} / \mathrm{mol}$ [80]. Such an accuracy of calculations is hardly suitable for describing "very close points in the crystal structure landscape" of crystals with conformationally mobile molecules, e.g., see [81].

\section{Conclusions}

The paper presents the synthesis of 2-[(E)-(phenylimino)methyl]phenol (SA) and its two deutero-derivatives (SA-OD and SA- $\mathbf{C}_{6} \mathbf{D}_{5}$ ). The bands corresponding to hydrogen bond vibrational modes (see Scheme 1) were assigned in experimental IR, IINS and Raman spectra. The analysis of the obtained spectral results proved that in a crystal state, SA exists in enol-imine form with a so-called quasi-aromatic intramolecular $\mathrm{OH} \cdots \mathrm{N}$ hydrogen bond of medium strength. The measured IINS spectra $\mathbf{S A}$ and $\mathbf{S A}-\mathbf{C}_{6} \mathbf{D}_{5}$ made it possible to show the influence of deuteron replacement in the remote group (aldimine ring) on the hydrogen bridge stretching vibrations $v_{\sigma}(\mathrm{OHN})$. The calculations of structure and vibrational spectra of two polymorphs (earlier studied by X-ray method [27]) performed by static periodic (solid state) DFT method showed a good agreement between the measured and calculated spectra, allowing for spectroscopic distinction between polymorphs $\alpha_{2}$ and $\beta$, as well as confirming the applicability of DFPT calculations for characterization of polymorphic states. Based on analysis of IR spectra, the SA in the studied samples was shown to exist in $\alpha$-form. However, the XPD measurements carried out for $\mathbf{S A}$ and $\mathbf{S A}-\mathbf{C}_{6} \mathbf{D}_{5}$ showed dual signals 
for several reflexes and did not show a phase transition in the temperature range from 20 to $295 \mathrm{~K}$. On the basis of these measurements two quasi-isostructural polymorphs of SA (most probably, so-called $\alpha_{1}$ and $\alpha_{2}$ forms) were assumed to co-exist in the mentioned temperature range.

Supplementary Materials: The following are available online, Figure S1: Normalized experimental Raman and IR spectra of SA and its deuterated derivative SA-OD. Figure S2: Temperature behaviour of XRD patterns for SA and $\mathbf{S A}-\mathbf{C}_{6} \mathbf{D}_{5}$. Figure S3: Temperature dependence of X-ray powder diffraction patterns of SA and SA-C6D5. Table S1: Definitions of the internal coordinates used in the potential energy distribution (PED) analysis for the assignments of the vibrational spectra, Table S2: Experimental IR, Raman, IINS and calculated (B3LYP/6-311+G(d,p)) spectral data of SA, Table S3: Experimental IR, Raman and calculated (B3LYP/6-311+G(d,p)) spectral data of SA-OD, Table S4: Experimental IINS and calculated (B3LYP/6-311+G(d,p)) spectral data of $\mathbf{S A}-\mathbf{C}_{6} \mathbf{D}_{5}$ for the region $0-1200 \mathrm{~cm}^{-1}$.

Author Contributions: Conceptualization, A.F.; methodology, A.F.; validation, all authors; formal analysis, A.F. and P.M.T.; investigation, Ł.H., E.A.G., J.W., M.V.V., P.L., P.M.T. and A.F.; resources, A.F. and P.M.T.; data curation, Ł.H., E.A.G., J.W., M.V.V., P.L., P.M.T. and A.F.; writing-original draft preparation, A.F.; writing-review and editing, A.F. and P.M.T.; visualization, Ł.H., E.A.G., J.W., M.V.V., P.L., P.M.T. and A.F.; supervision, A.F.; project administration, A.F.; funding acquisition, P.M.T. All authors have read and agreed to the published version of the manuscript.

Funding: This research was funded by the Russian Science Foundation (RFBR, grant no 18-13-00050) and Polish Government Plenipotentiary for JINR in Dubna (PWB/168-19/2021; data 11.03.2021).

Institutional Review Board Statement: Not applicable.

Informed Consent Statement: Not applicable.

Data Availability Statement: All data are available within the article or Supplementary Materials.

Acknowledgments: A.F. acknowledges the Wrocław Centre for Networking and Supercomputing Centres (WCSS) for providing computational time and facilities.

Conflicts of Interest: The authors declare no conflict of interest.

Sample Availability: Samples of the studied compounds are not available from the authors.

\section{References}

1. Schiff, H. Mittheilungen aus dem Universitätslaboratorium in Pisa Eine neue Reihe organischer Basen. Justus Liebigs Ann. Chem. 1864, 131, 118-119. [CrossRef]

2. Tidwell, T.T. Hugo (Ugo) Schiff, Schiff Bases, and a Century of $\beta$-Lactam Synthesis. Angew. Chem. 2008, 47, 1016-1020. [CrossRef]

3. Anselrnino, O. Isomere Schiff'sche Basen. Ber. Dtsch. Chem. Ges. 1905, 38, 3989-3997. [CrossRef]

4. Carletta, A.; Dubois, J.; Tilborg, A.; Wouters, J. Solid-state investigation on a new dimorphic substituted N-salicylidene compound: Insights into its thermochromic behaviour. CrystEngComm 2015, 17, 3509-3518. [CrossRef]

5. Ossowicz, P.; Janus, E.; Szady-Chelmieniecka, A.; Rozwadowski, Z. Influence of modification of the amino acids ionic liquids on their physico-chemical properties: Ionic liquids versus ionic liquids-supported Schiff bases. J. Mol. Liq. 2016, 224, 211-218. [CrossRef]

6. Liu, H.; Ye, K.; Zhang, Z.; Zhang, H. An Organic Crystal with High Elasticity at an Ultra-Low Temperature (77 K) and Shape ability at High Temperatures. Angew. Chem. Int. Ed. 2019, 58, 19081-19086. [CrossRef]

7. Napier, I.; Ponka, P.; Richardson, D.R. Iron trafficking in the mitochondrion: Novel pathways revealed by disease. Blood 2005, 105, 1867-1874. [CrossRef]

8. Kawato, T.; Koyama, H.; Kanatomi, H.; Shigemizu, H. Difference in the Rate of Photo-induced Unimolecular Motion of Chiral Salicylideneamines in the Chiral Crystal Environments. Chem. Lett. 1997, 26, 401-402. [CrossRef]

9. Koshima, H.; Matsuo, R.; Matsudomi, M.; Uemura, Y.; Shiro, M. Light-Driven Bending Crystals of Salicylidenephenylethylamines in Enantiomeric and Racemate Forms. Cryst. Growth Des. 2013, 13, 4330-4337. [CrossRef]

10. Takanabe, A.; Tanaka, M.; Johmoto, K.; Uekusa, H.; Mori, T.; Koshima, H.; Asahi, T. Optical Activity and Optical Anisotropy in Photomechanical Crystals of Chiral Salicylidenephenylethylamines. J. Am. Chem. Soc. 2016, 45, 15066-15077. [CrossRef]

11. Centore, R.; Jazbinsek, M.; Tuzi, A.; Roviello, A.; Capobianco, A.; Peluso, A. A series of compounds forming polar crystals and showing single-crystal-to-single-crystal transitions between polar phases. CrystEngComm 2012, 14, 2645-2653. [CrossRef]

12. Takanabe, A.; Katsufuji, T.; Johmoto, K.; Uekusa, H.; Shiro, M.; Koshima, H.; Asahi, T. Reversible Single-Crystal-to-Single-Crystal Phase Transition of Chiral Salicylidenephenylethylamine. Crystals 2017, 7, 7. [CrossRef] 
13. Cohen, M.D.; Schmidt, G.M. Photochromy and thermochromy of anils. J. Phys. Chem. 1962, 66, 2442-2446. [CrossRef]

14. Riddle, J.A.; Bollinger, J.C.; Lee, D. Escape from a Nonporous Solid: Mechanically Coupled Biconcave Molecules. Angew. Chem. Int. Ed. 2005, 44, 6689-6693. [CrossRef]

15. Jia, Y.; Li, J. Molecular Assembly of Schiff Base Interactions: Construction and Application. Chem. Rev. 2015, 115, 1597-1621. [CrossRef]

16. Kandappa, S.K.; Valloli, L.K.; Ahuja, S.; Parthiban, J.; Sivaguru, J. Taming the excited state reactivity of imines-from non-radiative decay to aza Paternó-Büchi reaction. Chem. Soc. Rev. 2021, 50, 1617-1641. [CrossRef] [PubMed]

17. Muriel, W.A.; Botero-Cadavid, J.F.; Cardenas, C.; Rodriguez-Cordoba, W. A theoretical study of the photodynamics of salicylidene2-anthrylamine in acetonitrile solution. Phys. Chem. Chem. Phys. 2018, 20, 29399-29411. [CrossRef] [PubMed]

18. Matamoros, E.; Cintas, P.; Light, M.E.; Palacios, J.C. Electronic effects in tautomeric equilibria: The case of chiral imines from d-glucamine and 2-hydroxyacetophenones. Org. Biomol. Chem. 2019, 17, 10209-10222. [CrossRef]

19. Filarowski, A.; Lopatkova, M.; Lipkowski, P.; Van der Auwerar, M.; Leen, V.; Dehaen, W. Solvatochromism of BODIPY-Schiff base Dye. J. Phys. Chem. B 2015, 119, 2576-2584. [CrossRef]

20. Cohen, M.D.; Schmidt, G.M.J.; Flavian, S. Topochemistry. Part VI. Experiments on photochromy and thermochromy of crystalline anils of salicylaldehydes. J. Chem. Soc. 1964, 2041-2051. [CrossRef]

21. Andes, R.V.; Manikowski, D.M. Photochromism of Salicylidene Aniline. Appl. Opt. 1968, 7, 1179-1183. [CrossRef]

22. Destro, R.; Gavezzotti, A.; Simonetta, M. Salicylideneaniline. Acta Crystallogr. 1978, 34, 2867-2869. [CrossRef]

23. Hadjoudis, E.; Vittorakis, M.; Moustakali-Mavridis, I. Photochromism of organic compounds in the crystal state. Tetrahedron 1987, 43, 1345-1360. [CrossRef]

24. Ogawa, K.; Kasahara, Y.; Ohtani, Y.; Harada, J. Crystal Structure Change for the Thermochromy of N-Salicylideneanilines. The First Observation by X-ray Diffraction. J. Am. Chem. Soc. 1998, 120, 7107-7108.

25. Gao, A.-H.; Wang, M.-S. Nonadiabatic ab initio molecular dynamics study of photoisomerization in $N$-salicilydenemethylfurylamine (SMFA). J. Chem. Phys. 2017, 146, 124312. [CrossRef] [PubMed]

26. Rawat, M.S.M.; Mal, S.; Singh, P. Photochromism in Anils-A Review. Open Chem. J. 2015, 2, 7-19. [CrossRef]

27. Arod, F.; Pattison, P.; Schenk, K.J.; Chapuis, G. Polymorphism in N-Salicylideneaniline Reconsidered. Cryst. Growth Des. 2007, 7, 1679-1685. [CrossRef]

28. Arod, F.; Gardon, M.; Pattison, P.; Chapuis, G. The $\alpha 2$-polymorph of salicylideneaniline. Acta Crystallogr. 2005, 61, o317-o320. [CrossRef]

29. Grzegorzek, J.; Filarowski, A.; Mielke, Z. The photoinduced isomerization and its implication in the photo-dynamical processes in two simple Schiff bases isolated in solid argon. Phys. Chem. Chem. Phys. 2011, 13, 16596-16605. [CrossRef]

30. Grzegorzek, J.; Mielke, Z.; Filarowski, A. C=N-N=C conformational isomers of 2'-hydroxyacetophenone azine: FTIR matrix isolation and DFT study. J. Mol. Struct. 2010, 976, 371-376. [CrossRef]

31. Sıdır, İ.; Gülseven Sıdır, Y.; Góbi, S.; Berber, H.; Fausto, R. Structural Relevance of Intramolecular H-Bonding in Ortho-Hydroxyaryl Schiff Bases: The Case of 3-(5-bromo-2-hydroxybenzylideneamino) Phenol. Molecules 2021, 26, 2814. [CrossRef] [PubMed]

32. Majerz, I.; Pawlukojć, A.; Sobczyk, L.; Dziembowska, T.; Grech, E.; Szady-Chełmieniecka, A. The infrared, Raman and inelastic neutron scattering studies on 5-nitro-N-salicylideneethylamine. J. Mol. Struct. 2000, 552, 243-247. [CrossRef]

33. Filarowski, A.; Koll, A.; Lipkowski, P.; Pawlukojć, A. Inelastic neutron scattering and vibrational spectra of 2-(N-methyl- $\alpha-$ iminoethyl)-phenol and 2-(N-methyliminoethyl)-phenol: Experimental and theoretical approach. J. Mol. Struct. 2008, 880, 97-108. [CrossRef]

34. Moosavi-Tekyeh, Z.; Dastani, N. Intramolecular hydrogen bonding in N-salicylideneaniline: FT-IR spectrum and quantum chemical calculations. J. Mol. Struct. 2015, 1102, 314-322. [CrossRef]

35. Pająk, J.; Maes, G.; De Borggraeve, W.M.; Boens, N.; Filarowski, A. Matrix-isolation FT-IR and theoretical investigation of the vibrational properties of the sterically hindered ortho-hydroxy acylaromatic Schiff bases. J. Mol. Struct. 2007, 844-845, 83-93. [CrossRef]

36. Dziembowska, T.; Szafran, M.; Katrusiak, A.; Rozwadowski, Z. Crystal structure of and solvent effect on tautomeric equilibrium in Schiff base derived from 2-hydroxy-1-naphthaldehyde and methylamine studied by X-ray diffraction, DFT, NMR and IR methods. J. Mol. Struct. 2009, 929, 32-42. [CrossRef]

37. Sobczyk, L.; Obrzud, M.; Filarowski, A. H/D Isotope Effects in Hydrogen Bonded Systems. Molecules 2013, 18, 4467-4476. [CrossRef]

38. Kwocz, A.; Panek, J.J.; Jezierska, A.; Hetmańczyk, Ł.; Pawlukojć, A.; Kochel, A.; Lipkowski, P.; Filarowski, A. A molecular roundabout: Triple cycle-arranged hydrogen bonds in light of experiment and theory. New J. Chem. 2018, 42, 19467-19477. [CrossRef]

39. Zundel, G. Easily Polarizable Hydrogen Bonds-Their Interactions with the Environment-IR Continuum and Anomalous Large Conductivity. In The Hydrogen Bond: Recent Developments in Theory and Experiments; Schuster, P., Zundel, G., Sandorfy, C., Eds.; North-Holland: Amsterdam, The Netherland, 1976; Volume 2, pp. 683-766.

40. Shigorin, D.N. Vodorodnaya Svyaz' (Hydrogen Bond); Sokolov, N.D., Chulanovsky, A.D., Eds.; Nauka: Moscow, Russia, $1964 ;$ p. 195.

41. Hadži, D.; Bratos, S. Vibrational spectroscopy of the hydrogen bond. In The Hydrogen Bond: Recent Developments in Theory and Experiments; Schuster, P., Zundel, G., Sandorfy, C., Eds.; North-Holland: Amsterdam, The Netherlands, 1976; Volume 2, pp. 565-611. 
42. Tsubomura, H. Nature of the Hydrogen Bond. III. The Measurement of the Infrared Absorption Intensities of Free and HydrogenBonded OH Bands. Theory of the Increase of the Intensity Due to the Hydrogen Bond. J. Chem. Soc. 1956, 24, 927. [CrossRef]

43. Hadzi, D. Absorption spectra and structure of some solid hydroxyazo-compounds. J. Chem. Soc. 1956, 2143-2150. [CrossRef]

44. Filarowski, A.; Koll, A. Intergrated intensity of $v_{\mathrm{s}}(\mathrm{OH})$ absorption bands in bent hydrogen bonds in ortho-dialkylaminomethyl phenols. Vib. Spectrosc. 1996, 12, 15-24. [CrossRef]

45. Filarowski, A.; Koll, A. Specificity of the intramolecular hydrogen bond. The differences in spectroscopic characteristics of the intermolecular and intramolecular H-bonds. Vib. Spectrosc. 1998, 17, 123-131. [CrossRef]

46. Takasuka, M.; Matsui, Y. Experimental Observations and CN D0/2 Calculations for Hydroxy Stretching Frequency Shifts, Intensities, and Hydrogen Bond Energies of Intramolecular Hydrogen Bonds in ortho-Substituted Phenols. J. Chem. Soc. Perkin II 1979, 1743-1750. [CrossRef]

47. Nguyen, Y.H.; Lampkin, B.J.; Venkatesh, A.; Ellern, A.; Rossini, A.J.; VanVeller, B. Open-Resonance-Assisted Hydrogen Bonds and Competing Quasiaromaticity. J. Org. Chem. 2018, 83, 9850-9857. [CrossRef]

48. Gilli, G.; Gilli, P. The Nature of the Hydrogen Bond: Outline of a Comprehensive Hydrogen Bond Theory; Oxford University Press: Oxford, UK, 2009.

49. Hetmańczyk, Ł.; Szklarz, P.; Kwocz, A.; Wierzejewska, M.; Pagacz-Kostrzewa, M.; Melnikov, M.Y.; Tolstoy, P.M.; Filarowski, A. Polymorphism and Conformational Equilibrium of Nitro-Acetophenone in Solid State and under Matrix Conditions. Molecules 2021, 26, 3109. [CrossRef]

50. Piękoś, P.; Jezierska, A.; Panek, J.J.; Goremychkin, E.A.; Pozharskii, A.F.; Antonov, A.S.; Tolstoy, P.M.; Filarowski, A. Symmetry/asymmetry of the NHN hydrogen bond in protonated 1,8-bis(dimethylamino)naphthalene. Symmetry 2020, $12,1924$. [CrossRef]

51. Jóźwiak, K.; Jezierska, A.; Panek, J.J.; Goremychkin, E.A.; Tolstoy, P.M.; Shenderovich, I.G.; Filarowski, A. Inter- vs. intra-molecular hydrogen bond patterns and proton dynamics in phthalic acid associates. Molecules 2020, 25, 4720. [CrossRef]

52. Prohens, R.; Barbas, R.; Font-Bardia, M. Morphotropism and "Quasi-Isostructurality" in the Three High Z' Concomitant Polymorphs of Efinaconazole. Cryst. Grow. Des. 2020, 20, 4238-4242. [CrossRef]

53. Kálmán, A.; Párkányi, L.; Argay, G. Classification of the isostructurality of organic molecules in the crystalline state. Acta Cryst. 1993, 49, 1039-1049. [CrossRef]

54. Dey, D.; Thomas, S.P.; Spackman, M.A.; Chopra, D. Quasi-isostructural polymorphism' in molecular crystals: Inputs from interaction hierarchy and energy frameworks. Chem. Commun. 2016, 52, 2141-2144. [CrossRef]

55. Fischer, J.; Lima, J.A.; Freire, P.T.C.; Melo, F.E.A.; Havenith, R.W.A.; Filho, J.M.; Broer, R.; Eckert, J.; Bordallo, H.N. Molecular flexibility and structural instabilities in crystalline L-methionine. Biophys. Chem. 2013, 180-181, 76-85. [CrossRef]

56. De Souza, J.M.; Freire, P.T.C.; Argyriou, D.N.; Stride, J.A.; Barthòs, M.; Kalceff, W.; Bordallo, H.N. Raman and Neutron Scattering Study of Partially Deuterated l-Alanine: Evidence of a Solid-Solid Phase Transition. ChemPhysChem 2009, 10, 3337-3343. [CrossRef]

57. Hetmańczyk, J.; Hetmańczyk, Ł.; Bilski, P.; Kozak, A. Complex water dynamics in crystalline [Ca(H2O)2](ReO4)2, studied by the vibrational spectroscopy and proton magnetic resonance. J. Mol. Struct. 2020, 1205, 127610. [CrossRef]

58. Szostak, E.; Hetmańczyk, J.; Migdał-Mikuli, A. Inelastic and elastic neutron scattering studies of the vibrational and reorientational dynamics, crystal structure and solid-solid phase transition in $[\mathrm{Mn}(\mathrm{OS}(\mathrm{CH} 3) 2) 6](\mathrm{ClO} 4) 2$ supported by theoretical (DFT) calculations. Spectrochim. Acta A 2015, 145, 368-375. [CrossRef] [PubMed]

59. Hetmańczyk, J.; Hetmańczyk, Ł.; Nowicka-Scheibe, J.; Pawlukojć, A.; Maurin, J.K.; Schilf, W. Structural, Thermal, and Vibrational Properties of N,N-Dimethylglycine-Chloranilic Acid-A New Co-Crystal Based on an Aliphatic Amino Acid. Materials 2021, 14, 3292. [CrossRef] [PubMed]

60. Shapenova, D.S.; Shiryaev, A.A.; Bolte, M.; Kukułka, M.; Szczepanik, D.W.; Hooper, J.; Babashkina, M.G.; Mahmoudi, G.; Mitoraj, M.P.; Safin, D.A. Resonance Assisted Hydrogen Bonding Phenomenon Unveiled from Both Experiment and Theory-An Example of New Family of Ethyl N-salicylideneglycinate Dyes. Chem. Eur. J. 2020, 26, 12987-12995. [CrossRef]

61. Safin, D.A.; Robeyns, K.; Babashkina, M.G.; Filinchuk, Y.; Rotaru, A.; Jureschi, C.; Mitoraj, M.P.; Hooper, J.; Brela, M.; Garcia, Y. Polymorphism driven optical properties of an anil dye. CrystEngComm 2016, 18, 7249-7259. [CrossRef]

62. Cruz-Cabeza, A.J.; Bernstein, J. Conformational Polymorphism. Chem. Rev. 2014, 114, 2170-2191. [CrossRef]

63. Becke, A.D. Density-functional thermochemistry. III. The role of exact exchange. J. Chem. Phys. 1993, 98, 5648-5652. [CrossRef]

64. Lee, C.; Yang, W.; Parr, R.G. Development of the Colle-Salvetti Correlation-Energy Formula into a Functional of the Electron Density. Phys. Rev. B 1988, 37, 785-789. [CrossRef] [PubMed]

65. McLean, A.D.; Chandler, G.S. Contracted Gaussian basis sets for molecular calculations. I. Second row atoms, Z=11-18. J. Chem. Phys. 1980, 72, 5639-5648. [CrossRef]

66. Krishnan, R.; Binkley, J.S.; Seeger, R.; Pople, J.A. Self-consistent molecular orbital methods. XX. A basis set for correlated wave functions. J. Chem. Phys. 1980, 72, 650-654. [CrossRef]

67. Frisch, M.J.; Pople, J.A.; Binkley, J.S. Self-consistent molecular orbital methods 25. Supplementary functions for Gaussian basis sets. J. Chem. Phys. 1984, 80, 3265-3269. [CrossRef]

68. Frisch, M.J.; Trucks, G.W.; Schlegel, H.B.; Scuseria, G.E.; Robb, M.A.; Cheeseman, J.R.; Scalmani, G.; Barone, V.; Petersson, G.A.; Nakatsuji, H.; et al. Gaussian 16, Revision C.01; Gaussian, Inc.: Wallingford, CT, USA, 2016.

69. Schaftenaar, G.; Noordik, J.H. Molden: A pre- and post-processing program for molecular and electronic structures. J. Comput. Aided Mol. Des. 2000, 14, 123-134. [CrossRef] 
70. Martin, J.M.L.; Van Alsenoy, C. GAR2PED; University of Antwerp: Antwerpen, Belgium, 1995.

71. Dovesi, R.; Orlando, R.; Civalleri, B.; Roetti, C.; Saunders, V.R.; Zicovich-Wilson, C.M. CRYSTAL: A computational tool for the $a b$ initio study of the electronic properties of crystals. Z. Kristallogr. 2005, 220, 571-573. [CrossRef]

72. Dovesi, R.; Saunders, V.R.; Roetti, C.; Orlando, R.; Zicovich-Wilson, C.M.; Pascale, F.; Civalleri, B.; Doll, K.; Harrison, N.M.; Bush, I.J.; et al. CRYSTAL09 User's Manual; University of Torino: Torino, Italy, 2009.

73. Grimme, S. Semiempirical GGA-type density functional constructed with a long-range dispersion correction. J. Comput. Chem. 2006, 27, 1787-1799. [CrossRef] [PubMed]

74. Surov, A.O.; Voronin, A.P.; Vener, M.V.; Churakov, A.V.; Perlovich, G.L. Specific features of supramolecular organisation and hydrogen bonding in proline cocrystals: A case study of fenamates and diclofenac. CrystEngComm 2018, 20, 6970-6981. [CrossRef]

75. Voronin, A.P.; Surov, A.O.; Churakov, A.V.; Parashchuk, O.D.; Rykounov, A.A.; Vener, M.V. Combined X-ray Crystallographic, IR/Raman Spectroscopic, and Periodic DFT Investigations of New Multicomponent Crystalline Forms of Anthelmintic Drugs: A Case Study of Carbendazim Maleate. Molecules 2020, 25, 2386. [CrossRef]

76. Surov, A.O.; Vasilev, N.A.; Churakov, A.V.; Parashchuk, O.D.; Artobolevskii, S.V.; Alatortsev, O.A.; Makhrov, D.E.; Vener, M.V. Two Faces of Water in the Formation and Stabilization of Multicomponent Crystals of Zwitterionic Drug-Like Compounds. Symmetry 2021, 13, 425. [CrossRef]

77. Vener, M.V.; Sauer, J. Environmental effects on vibrational proton dynamics in $\mathrm{H}_{5} \mathrm{O}_{2}{ }^{+}$: DFT study on crystalline $\mathrm{H}_{5} \mathrm{O}_{2}{ }^{+} \mathrm{ClO}_{4}{ }^{-}$. Phys. Chem. Chem. Phys. 2005, 7, 258-263. [CrossRef]

78. Sen, A.; Mitev, P.D.; Eriksson, A.; Hermansson, K. H-bond and electric field correlations for water in highly hydrated crystals. Int. J. Quantum Chem. 2016, 116, 67-80. [CrossRef]

79. Červinka, C.; Fulem, M. Cohesive properties of the crystalline phases of twenty proteinogenic $\alpha$-aminoacids from first-principles calculations. Phys. Chem. Chem. Phys. 2019, 21, 18501-18515. [CrossRef] [PubMed]

80. Beran, G.J.O. Modeling Polymorphic Molecular Crystals with Electronic Structure Theory. Chem. Rev. 2016, 116, 5567-5613. [CrossRef] [PubMed]

81. Surov, A.O.; Manin, A.N.; Voronin, A.P.; Churakov, A.V.; Perlovich, G.L.; Vener, M.V. Weak Interactions Cause Packing Polymorphism in Pharmaceutical Two-Component crystals. The case study of the Salicylamide Cocrystal. Cryst. Growth Des. 2017, 17, 1425-1437. [CrossRef] 